\title{
Produtos florestais não madeireiros e valoração ambiental da Floresta Nacional de Pacotuba, ES
}

\author{
Non-timber forest products and environmental valuation of the National Forest Pacotuba, ES \\ Eth Rocha da Silva ${ }^{1}$, Adriano Ribeiro de Mendonça ${ }^{1 *}$, Milton Marques Fernandes ${ }^{2}$, Henrique Machado \\ Dias $^{1}$ e Mayra Luiza Marques da Silva ${ }^{3}$
}

1Universidade Federal do Espirito Santo, Jerônimo Monteiro, ES. Brasil. *Autor para correspondência: adriano.mendonca@ufes.br. ${ }^{2}$ Universidade Federal de Sergipe, São Cristóvão, SE, Brasil.

${ }^{3}$ Universidade Federal de São João Del Rei, Sete Lagoas, MG, Brasil.

Submissão: 25/07/2018 / Aceite: 01/03/2019

\begin{abstract}
RESUMO
Este estudo teve como objetivo avaliar o potencial para extração de produtos florestais não madeireiros (PFNMs) e a valoração ambiental pela disposição a receber dos moradores da zona de amortecimento da Floresta Nacional (FLONA) de Pacotuba, estado do Espírito Santo. Foram aplicados formulários em uma amostra de 78 famílias, na comunidade de Monte Alegre, localizada na zona de amortecimento da FLONA de Pacotuba, para o levantamento etnobotânico de PFNMs e a disposição a receber para manter a cobertura florestal. O mapeamento do uso do solo da FLONA do Pacotuba e da zona de amortecimento foram obtidos por meio de uma imagem Landsat. Foi utilizado o método de valoração contingente por meio dos formulários, para estimar a disposição a receber para manter a cobertura florestal. Na FLONA de Pacotuba existe potencial para produzir PFNMs, com uma oferta principalmente para fins medicinais e ecológicos. O uso do solo demonstra que a FLONA do Pacotuba apresenta um alto percentual de cobertura florestal, no entanto a zona de amortecimento está com alto percentual de pastagem e uso do solo antrópico, sendo o pagamento por serviços ambientais (PSA) uma alternativa para aumentar a cobertura florestal na zona de amortecimento. A disposição a receber para manter a cobertura florestal dos proprietários na zona de amortecimento e na FLONA foi maior do que o PSA do estado do Espírito Santo, o que dificulta a adoção de um programa de pagamentos por serviços ambientais. O PSA do Espírito Santo, por meio do programa Reflorestar, associado ao manejo de PFNMs, principalmente medicinais e ecológicos, seriam alternativas para geração de renda e preservação da cobertura florestal.
\end{abstract}

PALAVRAS-CHAVE: ecologia da paisagem, serviço ambiental, floresta estacional semidecidual.

\begin{abstract}
This study aimed to evaluate the potential for the extraction of non-timber forest products (NTFPs) and environmental valuation by the willingness to receive from the residents of the damping zone of the National Forest (FLONA) of Pacotuba, state of Espírito Santo. Forms were applied in a sample of 78 families, in the community of Monte Alegre, located in the damping zone of the FLONA de Pacotuba, for the NTFPs ethnobotanical survey and the willingness to receive to maintain the forest cover. The mapping use of the soil Pacotuba FLONA and the damping zone were obtained through a Landsat image. The contingent valuation method was used using the forms to estimate the willingness to receive to maintain the forest cover. At FLONA de Pacotuba there is potential to produce NTFPs, with an offer mainly for medicinal and ecological purposes. The use of the soil demonstrates that the FLONA of Pacotuba presents a high percentage of forest cover, however the damping zone is with a high percentage of pasture and use of the soil Anthropic, with the payment for environmental services (PES) an alternative to increase the forest cover in the cushioning zone. The willingness to receive to maintain the forest cover of the owners in the damping zone and in the FLONA was greater than the PES of the state of Espírito Santo, which hinders the adoption of a payment program for environmental services. The PES of Espírito Santo, through the program Reflorestar, associated with the management of NTFPs, mainly medicinal and ecological, would be alternatives for income generation and preservation of the forest cover.
\end{abstract}

KEYWORDS: landscape ecology, environmental service, semideciduous forest. 


\section{INTRODUÇÃO}

A Mata Atlântica é um bioma caracterizado pela riqueza de espécies, elevado grau de endemismo e vulnerabilidade aos impactos antrópicos e é considerada pelos pesquisadores, como um dos Hotspots mundiais (MYERS et al. 2000, LAGOS \& MULLER 2007). No decorrer dos anos, desde a colonização portuguesa, a Mata Atlântica vem sofrendo impactos antrópicos, principalmente por abrigar $70 \%$ da população brasileira (VARJABEDIAN 2010). A existência de perturbações antrópicas tem chamado a atenção ao longo dos anos de ambientalistas para preservação dos remanescentes da Mata Atlântica.

Para minimizar estes impactos, houve a criação de legislações específicas para proteção e conservação do que ainda resta a partir do monitoramento das áreas de desmatamento. Criadas pela Lei no 9.985 de 18 de julho de 2000, as Unidades de Conservação (UCs), possuem o objetivo de preservar e conservar remanescentes florestais além do manejo florestal e o extrativismo de produtos florestais. As UCs são compostas por 12 categorias divididas em dois grupos: proteção integral e de uso sustentável. Dentro do grupo de Uso Sustentável encontram-se as Florestas Nacionais (FLONAs). Esse tipo de UC caracteriza-se por ser uma área com cobertura florestal de espécies nativas e plantadas (BRASIL 2000).

A retirada de madeira de espécies nativas das FLONAs, localizadas em áreas de Mata Atlântica, só é permitida em caráter excepcional (BRASIL 2006). Com isso, é fundamental que se promova o desenvolvimento dessas áreas e de sua zona de amortecimento $(Z A)$ por meio da geração de renda de outras fontes, como o pagamento por serviços ambientais e o manejo de produtos florestais não madeireiros (PFNMs).

Embora as alternativas de uso de PFNMs e serviços ambientais não despertem grande interesse para as indústrias madeireiras, elas podem ser de grande relevância para o desenvolvimento de comunidades locais, além de contribuir para a conservação dos remanescentes florestais (GUERRA et al. 2009). Na FLONA de Pacotuba, localizada no estado do Espírito Santo, em seu Plano de Manejo consta a promoção do manejo de uso múltiplo, assim como o desenvolvimento de métodos de exploração sustentável dos recursos naturais, como os PFNMs (ICMBIO 2011). Portanto, os PFNMs podem ser utilizados como fonte de geração de renda, principalmente para moradores das comunidades tradicionais, mas é limitada por algumas dificuldades como a falta de pesquisas sobre o mercado potencial de produtos e sobre os serviços ambientais gerados pelas florestas nativas.

Por exemplo, na Floresta Nacional do Tapajós existe a extração do óleo vegetal de andiroba e copaíba, realizada por famílias extrativistas. Entretanto, a falta de informações que os extrativistas têm sobre o mercado desses produtos é um fator limitante para uma maior agregação de valor aos produtos, bem como a carência de assistência técnica visando maior qualidade e valor aos PFNMs extraídos (SANTOS \& GUERRA 2010). O ICMBIO (2018), cita que Floresta Nacional do Tapajós além do manejo florestal madeireiro, existem outras atividades extrativistas como extração de látex, biojóias, móveis artesanais, açaí, produção de licores e polpas e mel, abrangendo uma população extrativista de 4 mil pessoas.

Além disso, a valoração ambiental pode ser aplicada com a finalidade de aferir valores monetários a determinado bem, recurso e/ou serviço, de forma a impedir que a supressão desses bens e serviços, aqui referidos como serviços ambientais, seja tratada pela economia como bens públicos (MEDEIROS et al. 2011), como no caso das FLONAs.

Nesse sentido, o conceito de serviços ambientais surgiu para demonstrar que as áreas naturais cumprem funções essenciais e que as florestas nativas não são obstáculos ao desenvolvimento econômico podendo gerar trabalho e renda à comunidade local. A partir dos benefícios (serviços ambientais) que o ecossistema produz, pode trazer, em contrapartida, a manutenção desses serviços à sociedade em geral, promovendo também a conservação e recuperação de áreas florestadas.

O pagamento por serviços ambientais consiste em quem utiliza de um serviço ambiental possa pagar pela manutenção e/ou recuperação das áreas naturais que geram os serviços ambientais. Neste contexto, a valoração ambiental é essencial para definir o quanto quem utiliza do serviço ambiental deve pagar aos proprietários das áreas naturais que promovam serviços ambientais pela manutenção e/ou recuperação.

Portanto, este estudo teve como objetivo avaliar o potencial para extração de produtos florestais não madeireiros e a valoração ambiental pela disposição a receber dos moradores da zona de amortecimento da Floresta Nacional de Pacotuba, ES.

\section{MATERIAL E MÉTODOS}

\section{Caracterização da área de estudo}

O presente estudo foi desenvolvido na Floresta Nacional de Pacotuba, localizada no município de Cachoeiro de Itapemirim, estado do Espírito Santo, nas coordenadas geográficas centrais $20^{\circ} 44^{\prime} 43^{\prime \prime} \mathrm{S}$ e $41^{\circ}$ 
17'29" W. Limita-se ao sul em parte com o Rio Itapemirim e a sede da Fazenda Experimental Bananal do Norte; ao norte com a comunidade Quilombola de Monte Alegre. A FLONA possui uma superfície aproximada de 450,29 hectares $(0,51 \%$ da área do município). A partir do mapeamento do uso do solo da ZA, selecionouse a comunidade quilombola de Monte Alegre, em função de sua maior proximidade com a FLONA e estar situada na ZA (Figura 1).

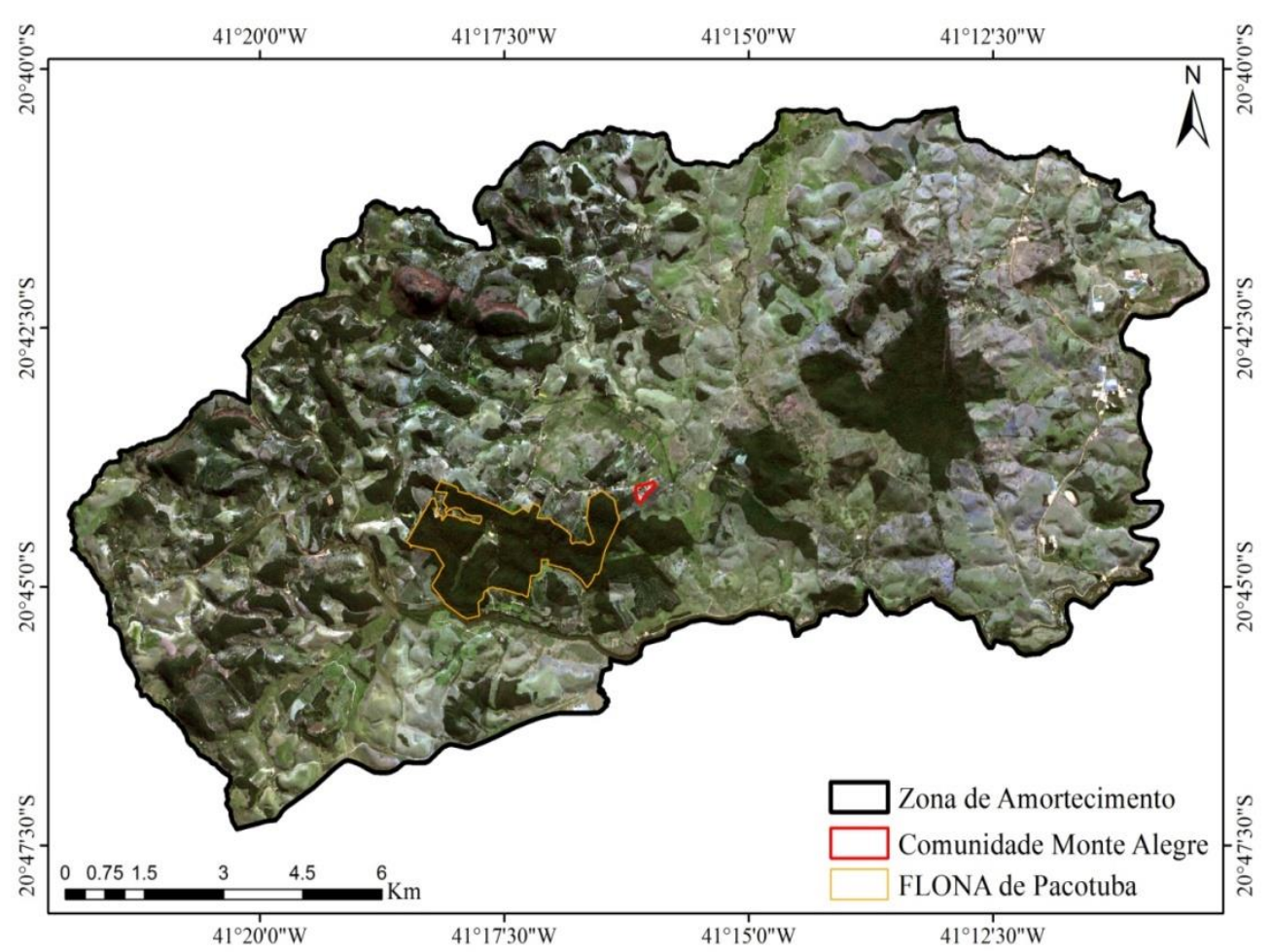

Figura 1. Mapa de localização da área de estudo.

Figure 1. Location map of the studied area.

Foi realizada uma pesquisa qualitativa e quantitativa conforme metodologia descrita em RAMIRES \& PESSÔA (2009), de caráter exploratório, composto por um levantamento por meio de entrevistas individuais. As entrevistas foram realizadas com questionários conforme descrito em SILVA (2016), na comunidade quilombola de Monte Alegre. A comunidade é formada por 130 famílias, totalizando 560 moradores, dos quais 450 são descendentes diretos de escravos. Essas famílias vivem em sua maioria da agricultura de subsistência (CORREIA et al. 2007).

O clima da região é tipo Cwa (ALVARES et al. 2013), com precipitação média anual de $1293 \mathrm{~mm}$ (PIROVANI et al. 2015). A temperatura média mínima mensal varia entre 12 e $18{ }^{\circ} \mathrm{C}$ e a média máxima mensal variando entre 31 e $34 \stackrel{\circ}{\circ}$ (PEZZOPANE et al. 2004). O tipo de solo predominante é Latossolo VermelhoAmarelo Distrófico (LVAd) (EMBRAPA 2006). A vegetação é classificada como Floresta Estacional Semidecidual Submontana (VELOSO et al. 1991).

\section{Coleta de dados}

O tamanho ótimo da amostra foi estimado de acordo com a metodologia proposta por GIL (1995), por meio da expressão (Equação 1), como utilizada por MATTOS et al. (2007).

$$
n=\frac{\delta^{2} \cdot p \cdot q \cdot N}{e^{2 \cdot}(N-1)+\delta^{2} \cdot p \cdot q}(1) \quad \text { (Equação 1) }
$$

Em que: $n=$ tamanho da amostra; $\delta^{2}=$ estimativa do nível de confiança escolhido (expresso em número de desvios-padrão); $p=$ probabilidade do fenômeno ocorrer; $q=1-p ; N=$ tamanho da população; $e=$ erro máximo admissível.

Para o cálculo do tamanho da amostra foi adotado dois desvios-padrão como nível de confiança, $p$ igual a 0,5 e o erro máximo admissível de $5 \%$. O tamanho da amostra obtido foi de 30 famílias. No entanto, optouse por realizar a entrevista em um número maior de residências, para deixar a amostra ainda mais representativa. Adotou-se o critério de amostrar todas as residências que foram possíveis de serem visitadas no decorrer de três dias, resultando em uma amostra de 78 residências (60\% das famílias e $13,92 \%$ dos moradores). Em cada residência foi entrevistado apenas um indivíduo com idade mínima de 16 anos. 


\section{Levantamento etnobotânico dos produtos florestais não madeireiros}

Para os moradores da comunidade de Monte Alegre, foi aplicado um formulário fechado conforme descrito em SILVA (2016), a fim de levantar informações socioeconômicas (renda, idade, escolaridade e sexo) e etnobotânicas, bem como identificar e qualificar a existência de produtos florestais não madeireiros na FLONA de Pacotuba.

Associado ao levantamento etnobotânico, foram utilizados dados de um levantamento fitossociológico realizado na FLONA por ABREU et al. (2013). Foram selecionadas as espécies arbóreas com densidade absoluta (DA) maior ou igual a cinco indivíduos por hectare. Após a seleção das espécies, foi realizado o levantamento sobre os usos das espécies baseadas em publicações disponibilizadas em revistas científicas, teses e dissertações. Com o intuito de identificar o potencial utilitário das espécies analisadas no levantamento, estas foram classificadas de acordo com as categorias utilizadas por ELIAS \& SANTOS (2016), a saber: a) ornamental: jardinagem, floricultura, decoração, arborização e/ou paisagismo, apícola; b) alimentícia e/ou aditivos: partes comestíveis utilizadas na alimentação humana/animal, incluindo condimentos e temperos; c) medicinal: medicina popular e/ou produto bioquímico de interesse farmacêutico, tanto para tratamentos de humanos quanto para uso veterinário; d) produtos bioquímicos: compostos químicos como taninos, corante, látex, goma, resina, óleo e toxina, entre outros de interesse farmacêutico ou químicoindustrial; e) ecológico: sementes e plântulas usadas em programas de reflorestamentos ou recuperação de áreas degradadas, agrossilvicultura, cortina vegetal ou recursos para a fauna; f) outros usos: usos diversos, não referenciados nas categorias anteriores, como por exemplo, o uso doméstico, para cobertura de casas, construção, sombreamento de cultivos, enchimento de travesseiros, jogos, fins religiosos ou místicos.

\section{Mapeamento do uso e ocupação do solo e zona de amortecimento da FLONA de Pacotuba}

Para obter a valoração ambiental da zona de amortecimento da FLONA de Pacotuba, foi realizado um mapeamento das áreas de florestas, bem como a identificação do uso e ocupação do solo. Para isso, o mapeamento de uso e ocupação do solo foi realizado a partir das imagens de 2015 do sensor OLI do Landsat 8, com resolução espacial de 30 metros.

O mapeamento da Floresta Nacional de Pacotuba foi feito por meio de uma classificação supervisionada, a partir das composições das bandas R6G5B4 (infravermelho de ondas curtas, infravermelho próximo e vermelho, respectivamente), na escala de 1:29.000. Foram utilizados como elementos de interpretação visual das imagens a tonalidade, formas e texturas. Em seguida, foram demarcadas cinco classes de uso do solo: curso d'água, floresta, campo sujo, solo exposto e pastagem (PIROVANI et al. 2015).

Para obter as classes de uso do solo na ZA da FLONA foi criado um buffer de $3 \mathrm{~km}$ na zona de amortecimento, similar ao utilizado por PIROVANI et al. (2015). Em seguida, foram recortados todos os excedentes fora da área de estudo e demarcadas sete classes: curso d'água, floresta, pastagem, cafezal, campo sujo, formação rochosa e solo exposto.

\section{Disposição a receber para preservar áreas florestais na zona de amortecimento e na FLONA do Pacotuba}

Para analisar a valoração ambiental das áreas florestais, foi utilizado o mesmo formulário aplicado para o levantamento etnobotânico na comunidade Monte Alegre. Para isso foi utilizado o método de valoração contingente (MVC).

Neste trabalho, optou-se em analisar a Disposição a Receber (DAR). Com isso, foi possível avaliar o quanto o proprietário estaria disposto a receber para manter intacta determinadas áreas de floresta de sua propriedade para garantir a provisão de serviços ambientais e ecossistêmicos. Para isso, foi calculada a média referente, apenas, as pessoas que se dispuseram a receber para preservar 1 (um) hectare de floresta. Este valor foi multiplicado pelo total de área florestal existente na FLONA e na sua ZA. Com o objetivo de verificar a correlação entre o grau de instrução dos entrevistados, a renda familiar e a idade com a DAR, realizou-se o teste do qui-quadrado $\left(X^{2}\right)$, ao nível de $5 \%$ de significância.

\section{RESULTADOS E DISCUSSÃO}

Levantamento etnobotânico dos produtos florestais não madeireiros da zona de amortecimento e da FLONA de Pacotuba

No levantamento realizado quanto ao conhecimento sobre PFNMs, observou-se que $67 \%$ conhecem o conceito de PFNMs e que 33\% desconhecem. Os produtos para fins medicinais são os mais conhecidos (49\%), devido alta utilização na fabricação de chás caseiros usados no tratamento de doenças à comunidade local. Diante do questionamento feito a pessoas mais idosas, os mesmos relataram dificuldades ao acesso de atendimento médico, assim, como já tinham conhecimento tradicional a respeito de produtos oriundos da floresta para cura de certas enfermidades, já se beneficiaram desses produtos ou conheciam pessoas que 
utilizavam. Para JUNIOR VEIGA et al. (2005), a utilização de plantas para fins medicinais, tratamento e prevenção de doenças é uma das formas mais antigas de prática medicinal da humanidade.

Dentre as espécies mais citadas pelos entrevistados estão a copaíba e o jatobá. Essas espécies também foram citadas como de uso medicinal pelos entrevistados na feira de Caruaru, Agreste de Pernambuco, nordeste do Brasil (ALMEIDA \& ALBUQUERQUE 2002). O óleo de copaíba é utilizado como anti-inflamatório das vias superiores e urinárias, tendo aplicação mais ampla como antisséptico e a casca do jatobá é utilizada em machucados e fraturas (JUNIOR VEIGA et al. 2005). RONCHI et al. (2016), avaliando o potencial medicinal de espécies florestais de um fragmento de uma Floresta Estacional Semidecidual em São Paulo, a copaíba foi citada para uso medicinal como anti-inflamatório e diurético.

Outra espécie também mencionada foi o pau-pereira, espécie encontrada em um levantamento do uso popular de plantas para fins medicinais pela população da cidade de Campos dos Goytacazes, RJ (PEREIRA et al. 2004).

Da categoria frutos/sementes (35\%), muitas espécies foram citadas como: jatobá que além das propriedades medicinais, também é utilizado para alimentação e produção de sementes, cajá do mato e pitomba. Já os usos para ornamentação foram citados por $13 \%$ dos entrevistados, sendo que as espécies mais citadas foram as samambaias e orquídeas, muito utilizadas para ornamentar quintais e casas.

O uso dos PFNMs é uma alternativa viável para diminuir a pressão sobre as florestas, de forma a permitir a exploração de recursos florestais sem degradar o ambiente e promovendo o desenvolvimento rural (GUERRA et al. 2009). A exploração desses produtos requer conhecimento prévio das espécies a serem coletadas, as técnicas que serão utilizadas nas colheitas desses produtos e seu rendimento para a comunidade beneficiada.

$\mathrm{Na}$ Tabela 1 são apresentadas as categorias de uso para todas as espécies com pelo menos cinco indivíduos por hectare, de acordo com a listagem florística e fitossociológica da FLONA de Pacotuba de ABREU et al. (2013).

Tabela 1. Categorias de uso de plantas com cinco ou mais indivíduos por hectare da Floresta Nacional de Pacotuba, ES.

Table 1. Plant use categories with five or more individuals per hectare of the National Forest of Pacotuba, ES.

Espécies/Família

\section{FABACEAE}

Abarema limae Iganci \& Morim M.P.

Albizia polycephala (H.B. \& K.) Killip

Anadenanthera peregrina (L.) Speg.

Parapiptadenia rigida (Benth.) Brenan

Pseudopiptadenia contorta (DC.) G.P. Lewis \& M.P.M. de Lima Ec (9)

Copaifera lucens Dwyer

Dalbergia nigra (Vell.) Allemao ex Benth.

Myrocarpus frondosus Allemao

Myroxylon peruiferum Linn.f.

Swartzia apetala Raddivar. apetala

Swartzia simplex var. ochnacea (DC.) R.S. Cowan

\section{EUPHORBIACEAE}

Senefeldera verticillata (Vell.) Croizat

NYCTAGINACEAE

Andradea floribunda Allemao

Guapira opposita (Vell.) Reitz

ANNONACEAE

Annona acutiflora Mart.

ANACARDIACEAE

Continua...

Categorias de uso/ autores Partes da planta

\subsection{1.}

Ec (7)

$\mathrm{Ec}, \operatorname{Or}(3,6,8,10)$

$\mathrm{Ec}(15), \mathrm{Pb}(14,16), \mathrm{Me}(14)$

Ec, Or (8)

$\mathrm{Me}(2)$

$\mathrm{Ec}(4,8)$, Or (8), $\mathrm{Pb}, \mathrm{Ou}(4)$

$\mathrm{Ec}(4,8), \mathrm{Or}(8), \mathrm{Pb}, \mathrm{Me}(4)$

Ec $(5,8)$

Or, $\mathrm{Aa}(9)$

Or, $\mathrm{Aa}(9)$

$\mathrm{Aa}, \mathrm{Ec}(8)$

Fr, Se

$\mathrm{Se}$

Se, Ár

$\mathrm{Se}, \mathrm{Ca}$

$\mathrm{Se}, \mathrm{FI}$

Se, Ár

$\mathrm{Ca}$

Se, Ár, Ca, Fl, La

$\mathrm{Se}, \mathrm{A} r, \mathrm{Ca}, \mathrm{Ca}, \mathrm{Fo}$

$\mathrm{Se}$

$\mathrm{FI}, \mathrm{Fr}$

$\mathrm{Fl}, \mathrm{Fr}$

$\mathrm{Fl}, \mathrm{Fr}$

$\mathrm{Aa}, \mathrm{Ec}(8)$

$\mathrm{Me}(8), \mathrm{Ec}(8,11)$
$\mathrm{Ec}, \mathrm{Aa}(8)$

Ah, Ec (8)

$\mathrm{Fr}, \mathrm{Se}$ 


\begin{tabular}{|c|c|c|}
\hline \multicolumn{3}{|l|}{ Tabela 1- Continuação } \\
\hline Astronium concinnum (Engl.) Schott & $\mathrm{Ec}, \mathrm{Aa}(8)$ & $\mathrm{Se}, \mathrm{Fr}$ \\
\hline Astronium graveolens Jacq. & Ec, Or (8) & Se, Ár \\
\hline \multicolumn{3}{|l|}{ MELIACEAE } \\
\hline Cedrela fissilis Vell. & $\mathrm{Ec}(4,8), \mathrm{Pb}, \mathrm{Aa}, \mathrm{Or}, \mathrm{Me}(4)$ & Ár, Se, Ca, Fr, Fl, Fo \\
\hline Guarea guidonia (L.) Sleumer & Ec (8) & Se \\
\hline Trichilia pallens C. DC. & Or, Ec (9), $\mathrm{Pb}(8)$ & Ár, Se, Ca \\
\hline Trichilia silvatica C. DC. & $\mathrm{Aa}, \mathrm{Ec}, \mathrm{Or}(8)$ & \\
\hline \multicolumn{3}{|l|}{ SAPINDACEAE } \\
\hline Pseudima frutescens (Aubl.) Radlk. & $\mathrm{Aa}, \mathrm{Ec}(8)$ & $\mathrm{Fr}, \mathrm{Se}$ \\
\hline \multicolumn{3}{|l|}{ ICACINACEAE } \\
\hline Citronella paniculata (Mart.) Howard & Or, Ec (8) & Ár, Se \\
\hline \multicolumn{3}{|l|}{ MORACEAE } \\
\hline Clarisia racemosa Ruiz \& Pav. & Ec (8) & Se \\
\hline \multicolumn{3}{|l|}{ Naucleopsis oblongifolia (Kuhlm.) Carauta } \\
\hline Sorocea guilleminiana Gaudich. & Or, $\mathrm{Aa}, \mathrm{Pb}(12)$ & $\mathrm{Ca}, \mathrm{Fl}, \mathrm{Fr}$ \\
\hline \multicolumn{3}{|l|}{ LECYTHIDACEAE } \\
\hline Courataria sterotricha Prance & Ec, Or (8) & Se, Ár \\
\hline Lecythis lurida (Miers) S.A. Mori & $\mathrm{Ec}, \mathrm{Aa}(8)$ & $\mathrm{Se}, \mathrm{Fr}$ \\
\hline \multicolumn{3}{|l|}{ RUTACEAE } \\
\hline Esenbeckia grandiflora Mart. subsp. Grandiflora & Or, Ec (8) & $\mathrm{Fl}, \mathrm{Se}$ \\
\hline Neoraputia alba (Nees \& Mart.) Emmerich & $\mathrm{Ec}, \mathrm{Me}(8)$ & Se, Ár, Ca \\
\hline \multicolumn{3}{|l|}{ LAURACEAE } \\
\hline Ocotea elegans Mez & Ec, Or, Aa (8) & $\mathrm{Se}, \mathrm{FI}, \mathrm{Fr}$ \\
\hline \multicolumn{3}{|l|}{ APOCYNACEAE } \\
\hline Geisso spermumlaeve (Vell.) Baill. & $\mathrm{Me}, \mathrm{Or}(8), \mathrm{Pb}(1,8)$ & $\mathrm{Ca}, \mathrm{Fl}$, Fo \\
\hline \multicolumn{3}{|l|}{ TILIACEAE } \\
\hline Luehea mediterranea (Vell.) Angely & Or, $\mathrm{Pb}, \mathrm{Aa}, \mathrm{Me}, \mathrm{Ec}(4)$ & $\mathrm{Ca}, \mathrm{Fl}, \mathrm{Ca}, \mathrm{Fr}, \mathrm{Fo}, \mathrm{Se}$ \\
\hline \multicolumn{3}{|l|}{ BIGNONIACEAE } \\
\hline Paratecoma peroba (Record \& Mell.) Kuhlm. & Or (8), Ec (8), Aa (8), & $\mathrm{Ca}, \mathrm{Fl}, \mathrm{Se}, \mathrm{Fr}, \mathrm{FI}$ \\
\hline Tabebuia cassinoides (Lam.) A.P. DC. & Or $(3,4,8)$, Ec $(3,4,8)$ & $\mathrm{Fl}, \mathrm{Se}, \mathrm{Ca}, \mathrm{Fr}, \mathrm{Se}$ \\
\hline Rinorea bahiensis (Moric.) Kuntze & Ec (9) & Se \\
\hline \multicolumn{3}{|l|}{ MYRISTICACEAE } \\
\hline Virola gardneri (A. DC.) Warb. & $\mathrm{Aa}, \mathrm{Ec}(9),, \mathrm{Pb}(8)$ & $\mathrm{Fr}, \mathrm{Se}, \mathrm{Ca}$ \\
\hline Virola oleifera (Schott) A.C. Smith & Or, Aa, Ah, Ec (8), $\mathrm{Pb}(8)$ & $\mathrm{Fl}, \mathrm{Fr}, \mathrm{Se}, \mathrm{Ca}$ \\
\hline \multicolumn{3}{|l|}{ RHAMNACEAE } \\
\hline Ziziphus glaziovii Warm. & Aa, Ec (8) & $\mathrm{Fr}, \mathrm{Se}$ \\
\hline Zollernia glabra (Spreng.) Yakovlev & Aa, Ec (9) & $\mathrm{Fr}, \mathrm{Se}$ \\
\hline
\end{tabular}

Em que: $\mathrm{Aa}=$ alimentação animal; $\mathrm{Ah}=$ alimentação humana; $\mathrm{Ar}=$ artesanato; $\mathrm{Ec}=$ ecológico; $\mathrm{Me}=$ medicinal; $\mathrm{Or}=$ ornamental; $\mathrm{Pb}=$ produto bioquímico e $\mathrm{Ou}=$ outros.

Autores: ALCARDE et al. (2010) (1), BARBOZA da SILVA et al. (2012) (2), BORGES et al. (2000) (3), CARVALHO (2003) (4), CARVALHO (2006) (5), COSTA \& PAULA (2012) (6), IGANCI \& MORIN (2012) (7), LORENZI (2002) (8), LORENZI (2009) (9), MEDEIROS (2009) (10), MOURA et al. (2015) (11), SANTOS (2005) (12), SOBRINHO et al. (2011) (13), SPINA et al. (2001) (14), WEBER et al. (2011) (15), SARTORI et al. (2014) (16). Partes da planta: Ár (árvore), Ca (casca), Se (semente), Fr (fruto), Fl (flor), Fo (folha).

O levantamento dos PFNMs foi realizado em 40 espécies arbóreas com pelo menos cinco indivíduos inventariadas por ABREU et al. (2013). Foram encontradas 128 citações de usos e dentre as categorias de usos mais citadas, destacam-se ecológico (40\%), ornamental (23\%), alimentação animal (16\%), produtos bioquímicos (11\%), medicinal (6\%), alimentação humana (3\%) e outros usos (1\%).

Das partes das plantas utilizadas, a que se destaca com maior percentagem foram as sementes (34\%). 
Esse fato é justificável pela maioria das espécies apresentarem como PFNM de origem ecológica, uma vez que elas podem ser utilizadas para fins de recuperação de áreas degradadas (ELIAS \& SANTOS 2016), conforme observado durante as entrevistas, na qual foram relatados e observados produção de mudas para plantio em áreas degradadas. Na sequência, a mais citada entre os usos foram os frutos (19\%) para uso na alimentação humana e alimentação animal. Na terceira posição vem a casca (18\%), caracterizada como de uso medicinal e utilizada para a extração de produtos bioquímicos.

As flores (15\%), por serem fundamentais no uso apícola, árvore (10\%), podem ser utilizadas tanto para recuperação de áreas quanto para fins ornamentais e paisagístico e as folhas (4\%) também utilizadas para uso medicinal e extração de produtos bioquímicos, também tiveram destaque. Neste estudo somente foram considerados os produtos florestais não madeireiros, desta forma usos para lenha ou escoras não foram considerados.

Das espécies com maiores citações de uso destacam-se: Luehea mediterranea, Cedrela fissilis, Virola oleifera com cinco categorias de usos de cada espécie. Essas espécies são caracterizadas principalmente para produção de sementes (BORGES et al. 2000, LORENZI 2002, CARVALHO 2003). Cedrela fissilis, espécie de rápido crescimento, além da produção de sementes extrai-se, também, óleo essencial e chás da casca são usados na medicina popular (LORENZI 2009). A Virola oleifera se destaca também para produção bioquímica, principalmente para estudos farmacológicos (LORENZI 2002).

Foi possível observar que tanto nas citações de usos das espécies do trabalho de ABREU et al. (2013) quanto, na caracterização etnobotânica realizada na FLONA de Pacotuba, que as espécies possuem potencial para uso como produtos florestais não madeireiros, principalmente para fins medicinais e ecológico.

\section{Mapeamento do uso e ocupação do solo e zona de amortecimento da FLONA de Pacotuba}

Por meio da imagem de satélite Landsat 8 foi possível identificar 5 categorias de uso do solo na FLONA de Pacotuba (Figura 2). A quantificação das áreas relativas a cada classe demonstrou que a área em estudo se apresenta, em sua maioria, ocupada por floresta nativa e plantada (Tabela 2).

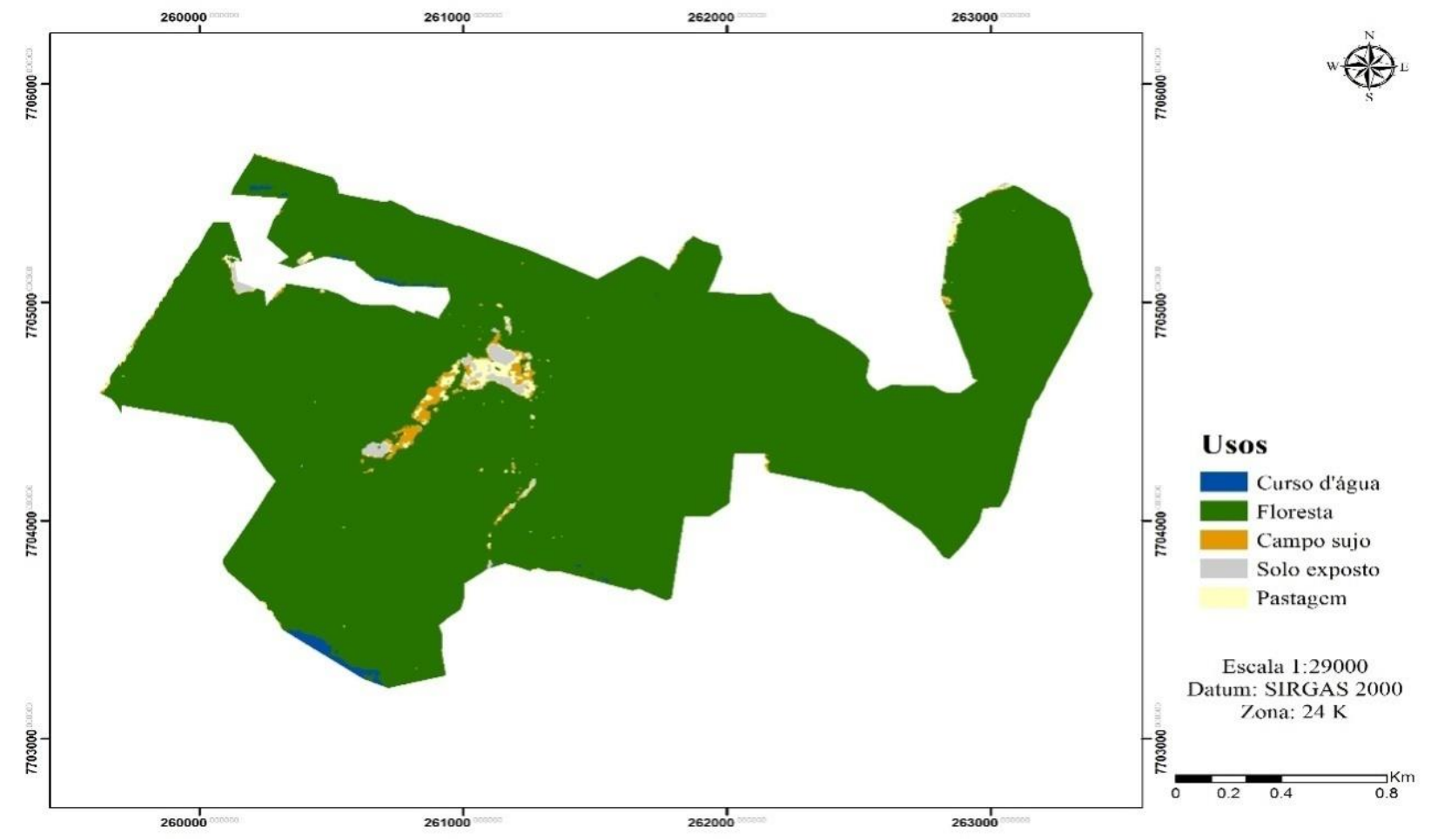

Figura 2. Uso e ocupação do solo da Floresta Nacional de Pacotuba, ES.

Figure 2. Use and land Occupation of the National Forest of Pacotuba, ES.

As áreas floresta nativa e plantada são divididas, de acordo com o plano de manejo da floresta nacional, em zonas de manejo e zona primitiva, sendo a zona de manejo as áreas com potencialidade para exploração de produtos florestais não madeireiros nas áreas nativas, e madeireiros na área plantada com espécies exóticas, como também, área com potencial para recuperação de ambientes e que, depois de recuperado, se transformará em área para o manejo florestal. A zona primitiva abrange as áreas com maior grau de regeneração e inclusão de ambientes frágeis, como nascentes. 
Tabela 2. Classe de uso do solo mapeada na Floresta Nacional de Pacotuba.

Table 2. Land use class mapped in the Pacotuba National Forest.

\begin{tabular}{lrc}
\hline \multirow{2}{*}{ Classe de uso e ocupação } & \multicolumn{2}{c}{ Área } \\
\cline { 2 - 3 } & \multicolumn{1}{c}{ ha } \\
\hline Curso d'água & 2,00 & 0,44 \\
Floresta & 438,08 & 97,01 \\
Campo sujo & 4,06 & 0,90 \\
Solo exposto & 3,25 & 0,72 \\
Pastagem & 4,19 & 0,93 \\
\hline Total & 451,58 & 100,00 \\
\hline
\end{tabular}

As classes de uso do solo campo sujo, solo exposto e pastagem são definidas no plano de manejo da Floresta Nacional de Pacotuba como áreas de usos conflitantes com redes de distribuição de energia e estradas que não são de interesse exclusivo da FLONA; na área de uso público, onde concentram-se as infraestruturas de apoio às demais atividades desenvolvidas na Unidade de Conservação (UC), em especial para a Gestão da Unidade.

Para o uso e ocupação do solo da zona de amortecimento (Figura 3) nota-se um percentual de aproximadamente $30 \%$ caracterizado como floresta (Tabela 3). PIROVANI et al. 2015, em estudos de uso e caracterização da terra realizados para o ano de 2007 na zona de amortecimento da FLONA de Pacotuba, encontraram valores percentuais menores para área de floresta $(23,44 \%)$. No entanto, verificou-se que no decorrer de nove anos essa área está tendo uma boa recuperação. A classe de pastagem apresentou o maior percentual com $40 \%$, seguida de solo exposto com $14 \%$. Dessa forma, existe pouca floresta e maior parte é uso antrópico o que é prejudicial a cobertura florestal. Assim, a adoção de um pagamento por serviço ambiental no âmbito do que já existe no Espírito Santo auxiliaria na manutenção da cobertura florestal da ZA.

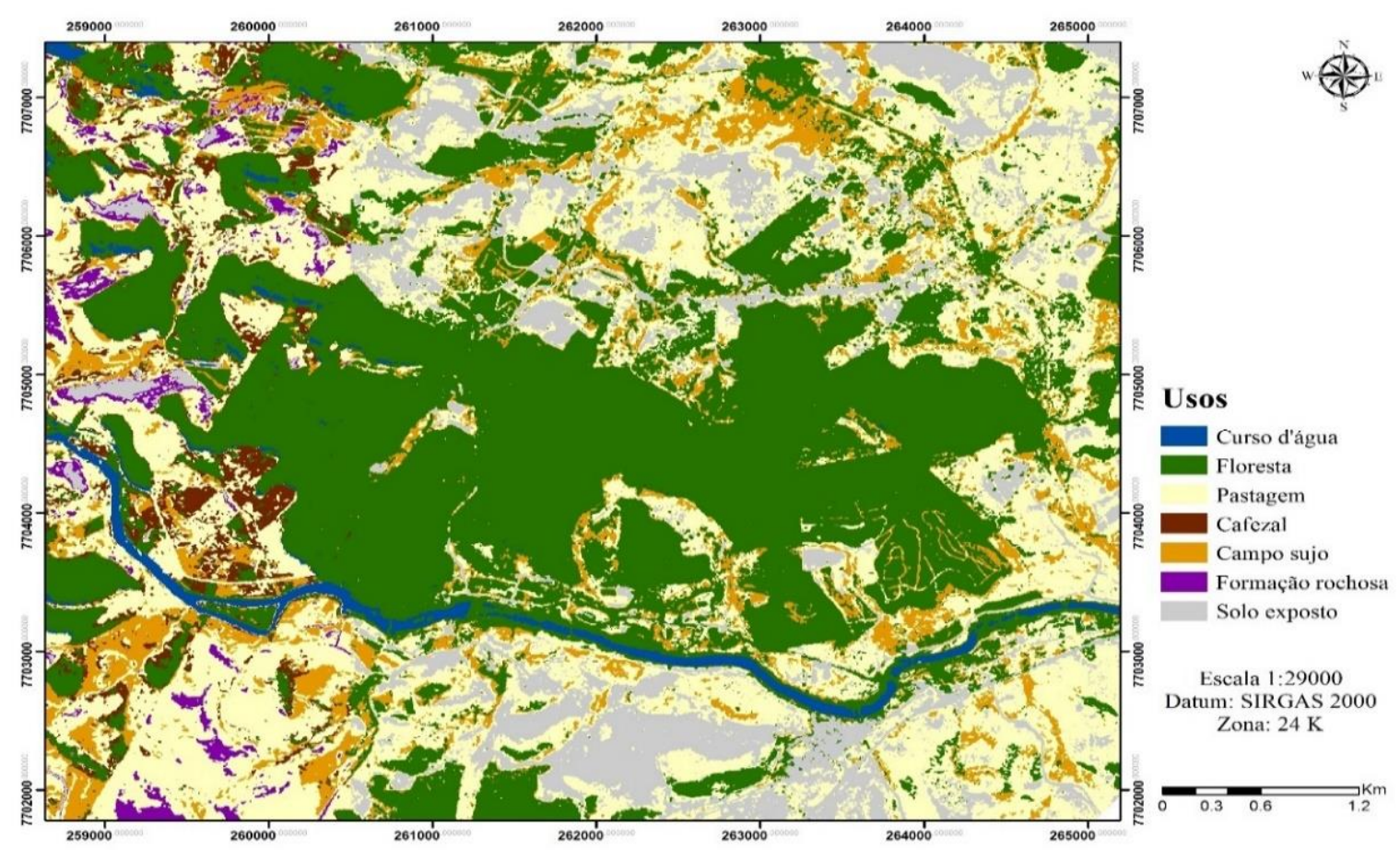

Figura 3. Uso e ocupação do solo da zona de amortecimento da Floresta Nacional de Pacotuba, ES. Figure 3. Use and soil Occupation in the buffer zone of the Pacotuba National Forest, ES.

Em estudos realizados em áreas de florestas no estado do Espírito Santo, foi possível identificar uma grande quantidade de áreas de pastagens como: PIROVANI et al. (2015) observaram no entorno da Reserva Particular de Patrimônio Natural (RPPN) Cafundó, que mais de $70 \%$ da paisagem é formada por pastagens. PIROVANI et al. (2015) afirmam que as pastagens na zona de amortecimento apresentam usos de práticas inadequadas de manejo do solo, como superpastejo que, pelo uso intensivo, compacta o solo e resulta em áreas de solo exposto a impacto direto e perda de qualidade. 
Tabela 3. Classes de uso e ocupação do solo da zona de amortecimento da FLONA de Pacotuba. Table 3. Classes of land use and occupation in the buffer zone of the Pacotuba FLONA.

\begin{tabular}{lrr}
\hline \multirow{2}{*}{ Classe de uso e ocupação } & \multicolumn{2}{c}{ Área } \\
\cline { 2 - 3 } & \multicolumn{1}{c}{ ha } \\
\hline Floresta & 1997,91 & 30,81 \\
Cafezal & 171,11 & 2,64 \\
Formação rochosa & 77,91 & 1,20 \\
Curso d'água & 101,28 & 1,56 \\
Campo sujo & 560,99 & 8,65 \\
Pastagem & 2626,27 & 40,50 \\
Solo exposto & 949,90 & 14,65 \\
\hline Total & 6485,36 & 100,00 \\
\hline
\end{tabular}

A RPPN Cafundó está localizada na bacia do rio Itapemirim, município de Cachoeiro de Itapemirim, região Sul do Espírito Santo, ligada a FLONA de Pacotuba por um micro corredor ecológico, BuraramaPacotuba-Cafundó. Devido essa proximidade da RPPN e a FLONA, o superpastejo, mencionado por PIROVANI et al. (2015), pode causar impactos na FLONA, por acarretar danos a vegetação e possíveis perdas de espécies valiosas, ou seja, espécies que apresentam alto valor comercial, pela sua raridade, beleza estética ou propriedades medicinais, alimentícias, entre outros aspectos, afetando a conectividade dos fragmentos da zona de amortecimento com os fragmentos dentro da FLONA.

GOBBO et al. (2016), em estudos realizados no PARNA-Caparaó encontraram 48\% da zona de amortecimento com pastagem. EUGENIO et al. (2010), ao caracterizarem uma área pertencente à microrregião denominada Caparaó Capixaba, no sul do Espírito Santo, constataram que as pastagens ocupam $67,82 \%$ da área estudada, valor superior ao encontrado neste trabalho.

\section{Disposição a receber para preservar áreas florestais na FLONA e zona de amortecimento}

Em relação a DAR para manter um hectare de Mata Atlântica na ZA e na FLONA de Pacotuba, 60\% concordam em receber um pagamento por serviços ambientais. Como consideram um custo de oportunidade, ou seja, as áreas de Mata Atlântica poderiam estar sendo utilizadas para uso agrícola ou pecuária, o pagamento por serviços ambientais seria viável, tornando os proprietários rurais enquadrados no princípio do protetor-recebedor.

Observou-se um percentual de $40 \%$ de entrevistados não dispostos a receber pagamentos por serviços ambientais para área de Mata Atlântica, o que pode estar associado a viés de protesto, como por exemplo que não é mais que obrigação do indivíduo a preservação da cobertura florestal. Quando o percentual de entrevistados for maior que $50 \%$ utilizando métodos de valoração contingente deve utilizar outra forma de valoração ambiental, pois este percentual estatisticamente não viabiliza a valoração ambiental.

A disposição a receber para manter um hectare de Mata Atlântica obteve os seguintes resultados: $45 \%$ dispostos a receber de $R \$ 500,00$ a $R \$ 1.000,00$ anualmente, $34 \%$ entre $R \$ 2.000,00$ a $R \$ 2.500,00$, sendo a classe de maior valor apresentado. Outros entrevistados estariam dispostos a receber entre $\mathrm{R} \$ 1.000,00 \mathrm{a}$ $R \$ 1.500,00(15 \%)$ anuais, $4 \%$ entre $R \$ 1.500,00$ a $R \$ 2.000,00$ anuais e $2 \%$ tiveram uma disposição a receber menos de $\mathrm{R} \$ 500,00$ anuais.

A média ponderada mostra que a disposição a receber seria de $\mathrm{R} \$ 1.343,75 \mathrm{ha}^{-1}$.ano-1. Este valor é considerado alto quando comparado ao valor encontrado por ANSOLIN et al. (2018) que observaram um custo de oportunidade de $\mathrm{R} \$ 945,00 \mathrm{ha}^{-1}$. ano-1. Ou seja, o custo de oportunidade refere-se a renda sacrificada pelo não uso da área de floresta para uso agrícola ou pecuário.

O estado do Espírito Santo possui um programa de pagamentos por serviços ambientais denominado Reflorestar, que remunera com $\mathrm{R} \$ 241,84 \mathrm{ha}^{-1}$.ano-1 de floresta em pé. Utilizando informações do percentual de cobertura florestal desta área, o PSA do programa Reflorestar geraria uma renda de $\mathrm{R} \$ 105.945,26$ ano $^{-1}$ para a FLONA e de $483.174,55$ para a ZA.

Já considerando a média dos valores da disposição a receber $\left(\mathrm{R} \$ 1.343,75 \mathrm{ha}^{-1}\right.$.ano-1), multiplicada pela área de floresta existente na ZA da FLONA (1997,91 ha) e, quando implementado um programa de pagamento por serviços ambientais a renda a ser gerada seria de aproximadamente $R \$ 2.684 .691,56$.ano ${ }^{-1}$ e considerando a área de floresta existente na FLONA (438,00 ha) um valor aproximado de $R \$ 588.670,00$ .ano ${ }^{-1}$. Os valores de PSA, utilizando a média da DAR obtida neste estudo para a FLONA e sua ZA, foram 
maiores que o estimado pelo programa Reflorestar, o que dificultaria um PSA considerando a DAR da comunidade Monte Alegre.

Por meio do teste qui-quadrado, entre a DAR e as variáveis grau de instrução, renda familiar e idade, verificou-se que não houve associação entre as variáveis, ou seja, não se rejeita a hipótese que o grau de instrução dos entrevistados e a disposição a receber são independentes, da mesma forma que a renda familiar e idade, a $5 \%$ de significância.

A maioria dos entrevistados (83\%) não possuem conhecimento sobre o termo PSA. Uma campanha de educação ambiental pode auxiliar no esclarecimento a respeito do PSA. De acordo com MURADIAN et al. (2010), o PSA pode influenciar positivamente a oferta de serviços ambientais a partir da sua escolha em adotar práticas agrícolas diversificadas e sustentáveis em uma área (Sistemas agroflorestais - SAFs e agricultura orgânica, etc.) em detrimento de atividades potencialmente degradantes (pecuária mal manejada e agricultura convencional).

\section{CONCLUSÃO}

Na FLONA de Pacotuba existe potencial para produzir produtos florestais não madeireiros, com uma oferta principalmente para fins medicinais e ecológicos.

A disposição a receber para manter a cobertura florestal dos proprietários na zona de amortecimento e na FLONA foi maior do que o PSE do estado do Espírito Santo, o que dificulta a adoção de um programa de pagamentos por serviços ambientais.

O PSA do Espírito Santo, por meio do programa Reflorestar, associado ao manejo de PFNMs, principalmente medicinais e ecológicos, seriam alternativas para geração de renda e preservação da cobertura florestal.

\section{REFERÊNCIAS}

ABREU KMPAK et al. 2013. Análise fitossociológica da floresta nacional de Pacotuba, Cachoeiro de Itapemirim, ES Brasil. Cerne 19: 157-168.

ALCARDE AR et al. 2010. Aspectos da composição química e aceitação sensorial da aguardente de cana-de-açúcar envelhecida em tonéis de diferentes madeiras. Ciência e Tecnologia de Alimentos 30: 226-232.

ALMEIDA CFCBG \& ALBUQUERQUE LP. 2002. Uso e conservação de plantas e animais medicinais no estado de Pernambuco (Nordeste do Brasil): um estudo de caso. Interciência 27: 276-285.

ALVARES CA et al. 2013. Köppen's climate classification map for Brazil. Meteorologische Zeitschrift 22: 711-728.

ANSOLIN RD et al. 2018. Valoração ambiental em áreas de preservação permanente na bacia hidrográfica do Rio Passaúna, Estado do Paraná. Revista de Ciências Agroveterinárias 17: 118-127.

BARBOZA da SILVA NC et al. 2012. Uso de plantas medicinais na comunidade quilombola da Barra II - Bahia, Brasil. Boletín Latino americano y del Caribe de Plantas Medicinales y Aromáticas 11: 435-453.

BORGES KH et al. 2000. Produção de sementes e o manejo da caixeta (Tabebuia cassinoides). Scientia Forestalis 57: 111-122.

BRASIL. 2006. A Lei Federal no 11.428 - Lei da Mata Atlântica, regula a conservação, a proteção, a regeneração e a utilização da Mata Atlântica. Presidência da República Casa Civil: Subchefia para Assuntos Jurídicos.

BRASIL. 2000. Lei no 9.985, de 18 de julho de 2000. Sistema Nacional de Unidades de Conservação. Diário Oficial da República Federativa do Brasil.

CARVALHO PER. 2003. Espécies arbóreas brasileiras. 1.ed. Brasília: Embrapa Informação Tecnológica.1039p.

CARVALHO PER. 2006. Espécies arbóreas brasileiras. 2.ed. Brasília: Embrapa Informação Tecnológica. 308p.

CORREIA W et al. 2007. Programa transdisciplinar para o desenvolvimento sustentável da comunidade quilombola de Monte Alegre. Revista Brasileira de Pesquisa em Turismo 1: 4-53.

COSTA EM \& PAULA RCA. 2012. Levantamento preliminar dos insetos associados às sementes de Albizia polycephala Benth em Vitória da Conquista-BA. Scientia plena 8: 1-5.

EMBRAPA. 2006. Empresa Brasileira de Agropecuária. Sistema brasileiro de classificação de solos. 2.ed. Rio de Janeiro: EMBRAPA Solos. 410p.

ELIAS GA \& SANTOS R. 2016. Produtos florestais não madeireiros e valor potencial de exploração sustentável da Floresta Atlântica no Sul de Santa Catarina. Ciência Florestal 26: 249-262.

EUGENIO FC et al. 2010. Confronto do uso e cobertura da terra em áreas de preservação permanente da bacia hidrográfica do rio alegre no município de Alegre, Espírito Santo. Engenharia Ambiental: Pesquisa e Tecnologia 7: 110126.

GIL AC. 1995. Métodos e técnicas de pesquisa social. 4.ed. São Paulo: Atlas. 220p.

GOBBO SDA et al. 2016. Uso da Terra no Entorno do PARNA-Caparaó: Preocupação com Incêndios Florestais. Floresta e Ambiente 23: 350-361.

GUERRA FGPQ et al. 2009. Quantificação e valoração de produtos não madeireiros. Floresta 39: 431-439.

ICMBIO. 2011. Plano de manejo da floresta nacional de Pacotuba, localizada no estado do Espírito Santo. Vila Velha: FAUNATIVA. 188p. 
ICMBIO. 2018. A Floresta Nacional do Tapajós. Disponível em: http://www.icmbio.gov.br/FLONAtapajos/. Acesso em: 30 out. 2018.

IGANCI JRV \& MORIM MP. 2012. Coleções botânicas para conservação: um estudo de caso em Abarema Pittier (Leguminosae, Mimosoideae). Revista Brasileira de Biociências 10: 164-170.

JUNIOR VEIGA V et al. 2005. Plantas medicinais: cura segura. Química nova 28: 519-528.

LAGOS AR \& MULLER BLA. 2007. Hotspot brasileiro Mata Atlântica. Saúde e Ambiente em Revista 2: 35-45.

LORENZI H. 2009. Árvores brasileiras: manual de identificação e cultivo de plantas arbóreas do Brasil. 4.ed. Nova Odessa: Instituto Plantarum. 298p.

LORENZI H. 2002. Árvores brasileiras: manual de identificação e cultivo de plantas arbóreas do Brasil. 2.ed. Nova Odessa: Instituto Plantarum. 234p.

MATTOS ADM et al. 2007. Valoração ambiental de áreas de preservação permanente da microbacia do ribeirão são Bartolomeu no município de Viçosa, MG. Revista Árvore 31: 347-353.

MEDEIROS R et al. 2011. Contribuição das unidades de conservação brasileiras para a economia nacional: Sumário Executivo, Brasília: UNEP-WCMC. 44p.

MOURA APC et al. 2015. Rooting of bougainvillea cuttings with concentrations of naphthalene acetic acid. Scientia Agraria 16: 57-61.

MURADIAN R et al. 2010. Reconciling theory and practice: An alternative conceptual framework for understanding payments for environmental services. Ecological Economics 69: 1202-1208.

MYERS N et al. 2000. Biodiversity hotspots for conservation priorities. Nature 403: 853-858.

PEREIRA RC et al. 2004. Plantas utilizadas como medicinais no município de Campos de Goytacazes-RJ. Revista Brasileira de Farmacognosia 14: 37- 40.

PEZZOPANE JEM et al. 2004. Espacialização da temperatura do ar do Estado do Espírito Santo. Revista Brasileira de Agrometeorologia 12: 151-158.

PIROVANI DB et al. 2015. Análise da paisagem e mudanças no uso da terra no entorno da RPPN Cafundó, ES. Cerne 21: 27-35.

RAMIRES JCL \& PESSÔA VLS. 2009. Geografia e pesquisa qualitativa nas trilhas da investigação. 1.ed. Uberlândia: Assis. 543p.

$\mathrm{RONCHI} \mathrm{HS}$ et al. 2016. Potencial medicinal de espécies arbóreas de um remanescente florestal da floresta estacional semidecidual, na região central do estado de São Paulo. Enciclopédia Biosfera 13: 986-1001.

SANTOS AJ \& GUERRA FGPQ. 2010. Aspectos econômicos da cadeia produtiva dos óleos de andiroba (Carapa guianensis Aubl.) e copaíba (Copaifera multijuga Hayne) na Floresta Nacional de Tapajós - Pará. Floresta 40: 23-28.

SANTOS MAS. 2005. A cadeia produtiva da pesca artesanal no estado do Pará: estudo de caso no nordeste paraense. Amazônia. Ciência e Desenvolvimento 1:61-81.

SARTORI CJ. et al. 2014. Teores de fenóis totais e taninos nas cascas de angico-vermelho (Anadenanthera peregrina). Floresta e Ambiente 21: 394-400.

SILVA ER. 2016. Produtos florestais não madeireiros e valoração ambiental da Floresta Nacional de Pacotuba, ES. Dissertação (Mestrado em Ciências Florestais). Jerônimo Monteiro: UFES. 50p.

SOBRINHO FAP et al. 2011. Uso de plantas medicinais no entorno da Reserva Biológica de Tinguá, Nova lguaçu, RJ. Ciências Agrárias e Ambiente 9: 195-206.

SPINA AP et al. 2001. Floração, frutificação e síndromes de dispersão de uma comunidade de floresta de brejo na região de campinas (SP). Acta Botânica Brasílica 15: 349-368.

VARJABEDIAN R. 2010. Lei da Mata Atlântica: retrocesso ambiental. Estudos avançados 24: 147-160.

VELOSO HP et al. 1991. Classificação da vegetação brasileira, adaptada a um sistema universal. 1.ed. Brasília: IBGE. 540p.

WEBER CR et al. 2011. Anadenanthera colubrina: um estudo do potencial terapêutico. Revista Brasileira Farmácia 92 : 235-244. 